\title{
云南高黎贡山怒族对植物传统利用的初步研究
}

\author{
刀志灵 龙春林* 刘怡涛 \\ (中国科学院昆明植物研究所, 昆明 650204)
}

\begin{abstract}
摘要: 采用民族生物学和文化人类学等方法, 广泛调查和研究了云南西北部高黎贡山地区怒族对植物的传统利用 形式。结果表明:怒族对植物的传统利用主要表现在食用、药用、观赏、宗教崇拜和文化利用等方面。讨论了怒族 的传统文化在当地植物多样性利用和管理中的作用和意义, 并探讨了在植物多样性管理中传统管理和现代管理之 间的关系以及在我国利用文化多样性进行自然生态环境保护的可能性、必要性和可行性。此外, 面对优秀的传统 文化知识和文化多样性逐渐消失的现实, 作者建议加以拯救和广泛的研究。
\end{abstract}

关键词: 植物多样性, 传统知识, 文化多样性

中图分类号:Q16文献标识码：A 文章编号：1005-0094(2003)03-0231-09

\section{On traditional uses of plants by the Nu people community of the Gaoli- gong Mountains, Yunnan Province}

DAO Zhi-Ling, LONG Chun-Lin * , LIU Yi-Tao

Kunming Institute of Botany, Chinese Academy of Sciences , Kunming 650204

\begin{abstract}
We studied the traditional uses of plants for different purposes by the $\mathrm{Nu}$ people in north Gaoligong Mountains region, northwestern Yunnan, through the approaches of ethnobiology, cultural anthropology and plant ecology. The results show that the $\mathrm{Nu}$ people traditionally use plants for food, herbal medicine, ornament, religious worship, and culture. Most of the plants are used for individual household consumption and some for exchanging with other nationalities or selling at local markets. Indigenous $\mathrm{Nu}$ people have been depending on plants for survival and development for a long time. Traditionally, wild plant resources play a very important role in the $\mathrm{Nu}$ people communities. Up to now, herbal plants are still the main medicine used by the $\mathrm{Nu}$ people. Fifty-four species of edible plants , 53 species of medicinal plants , 54 species of ornamental plants, and 51 species of cultural and religious plants frequently used by $\mathrm{Nu}$ people were listed in the present paper, as well as the impact of traditional culture upon utilization and management of local plant diversity. The relationship between traditional and modern management of plant diversity is discussed. The possibility, necessity and feasibility to utilize indigenous cultural diversity for ecological and environmental conservation in China are discussed and proposed. In addition , we suggest that the indigenous resource management knowledge and culture diversity should be conserved and extensively studied.
\end{abstract}

Key words : plant diversity, indigenous knowledge , cultural diversity

1
X

引言

我国是多民族、多文化的国家，不同民族的人们 对自然环境尤其是当地的生物资源的依赖性与利用
方式多种多样, 不仅深刻地影响和塑造了民族的文 化, 而且对生物多样性的利用、保护与管理产生着深 刻的影响 (张新时，1995)。近年来，不同民族对植 物资源利用的传统知识在学术界引起了广泛的注

基金项目：德国技术援助机构（German Development Cooperation，GTZ 00.2047.8-001.02)、美国国家科学基金 (National Science Foundation of USA, DEB-0103795)、国家自然科学基金（30170102）、云南省基金（1999C0078M，2001C0058M \& 2001PY017) 和国家科技部基金 (2001DEA10009) 
意，不少学者对此进行了研究和报道，如对植物的传 统利用（食用、药用等）(裴盛基, 1982; Long \& Wang，1995)、植物信仰或禁忌的调查研究 (Changkija，1996)、神圣植物 (sacred plants) 的民族 植物学研究 (Upadhye et al. , 1997 ; Viswanathan, 1997 ) 及以文化为背景的生物多样性利用和管理的 研究等 (Pei，1985; 许再富，刘宏茂，1995; 杨昌岩 等，1995; 龙春林等，1999a，1999b，1999c; 刘爱忠 等，2000; 龙春林等，2000)。

怒族是云南特有的少数民族之一, 是怒江高黎 贡山地区最早的土著居民 (indigenous people) ,我国 $95 \%$ 以上的怒族人居住在怒江州 (陶天麟，1997)。 但长期以来, 对怒族的研究大多限于民族学方面, 把 民族、经济、社会、文化、环境等结合起来的研究极少 (云南省编辑委员会，1981; 段伶，1991; 陶天麟， 1997)。怒江州贡山县是独龙族怒族自治县,怒族 有 6000 多人，占总人口的 $18.4 \%$ (贡山独龙族、怒 族自治县概况编写组，1986)。尽管当地怒族和藏 族杂居并且相互通婚，在风俗习惯、宗教、文化等方 面都相互影响，但怒族仍然保持着本身的明显特征。 贡山的怒族对当地丰富的植物资源利用已有 1000 多年的历史，他们的衣食住行无不与当地的植物多 样性有着密切的联系。植物资源, 特别是食用植物、 药用植物同贡山怒族的生产、生活密切相关,也是他 们经济收入的主要来源之一, 研究贡山怒族植物资 源的利用和管理,可以深入了解怒族的经济、社会、 文化等各方面的情况，对当地怒族弘扬传统文化、发 展当地经济有着重要的意义。因此, 本研究从植物 资源的利用形式入手，力图把怒族的经济、社会、文 化、环境保护等方面结合起来，通过研究贡山怒族在 这些方面的发展变化和相互影响，以求对贡山怒族 进行更全面深入的了解。同时,通过总结贡山怒族 优秀的传统文化和技术知识,发现他们在植物资源 方面的管理和利用中存在的问题，找出解决办法 将 有利于促进当地植物多样性的可持续利用，使当地 社区达到生态环境、自然资源、经济、文化和社会的 协调发展。

\section{2 研究方法}

本研究主要采用民族生物学 (ethnobiology)（裴 盛基, 龙春林, 1998)、文化人类学 (cultural anthropology ) ( Etkin , 1993 ; 汪宁生 , 1996 ; Rao , 1996) 和
植物生态学 ( plant ecology) ( Hedberg，1993; Begosst，1996)的方法，并进行了广泛的野外调查、 民间访谈和室内的整理分析。在多次野外调查中， 定点和跑点相结合, 着重采用植物分类学 (plant taxonomy)、关键人物访谈法 (key-informant interview)、 半结构访谈法 (semi-structured interview) 和参与式 方法的应用 (participatory rural appraisal, PRA) ( Lipp , 1989；Aba \& Brito，1996；龙春林，王洁如， 1996 ）对植物传统利用的现状做了详细的考察和 访问,并采集相关的凭证标本 (voucher) 和参阅馆藏 标本。在室内工作中，结合跨学科的文献研究，着重 凭证标本的鉴定、植物传统利用的方式、目的及其文 化内涵的编目（Waller，1993），并就传统文化对当 地植物资源、植物多样性的影响进行分析。

\section{3 研究地区}

为了使本研究既有代表性又有普遍性，选择了 位于贡山县高黎贡山国家级自然保护区缓冲带 (buffer zone) 的丙中洛乡作为定点研究地区。该地 区地处怒江大峡谷中上游地带, 东部为碧罗雪山, 西 部为高黎贡山, 属典型的立体气候, 从海拔 $1400 \sim$ $5100 \mathrm{~m}$ 地带上容纳了暖性、温性及寒温性的各种植 被类型。主要的自然植被从湿性常绿阔叶林开始 $(1400 \sim 1800 \mathrm{~m})$, 向上依次为中山湿性常绿阔叶林 $(1900 \sim 2600 \mathrm{~m}$ ) 、铁杉针阔叶混交林 (2600 2900 m) 、冷杉林 (2900 3400 m) 及高山灌丛与草甸 (3300 m 以上)(刘伦辉等, 2000)。这些地区有着 悠久的怒族居住历史和丰富的植物文化积淀，在地 理分布和传统怒族文化上有一定的普遍性和代表 性。

\section{4 研究结果}

怒族对植物的传统利用主要在食用、药用、观 赏、文化、宗教等方面。

\section{1 怒族的食用植物}

怒族大多生活在依山傍水的河流冲积扇地带， 家家户户都有水田、轮歇地和菜园地，栽种着适于当 地气候和生境的多种作物、蔬菜和果树。此外，他们 还依靠采集野生植物 (森林小产品) 补足日常消费 和调节膀食，包括水生、块茎和叶茎类食用植物，以 及食用菌类、竹笋和野果等。采集所获的野生食用 植物是怒族不可缺少的食物来源，仅有少数在集市 销售，成为家庭的副业收入。野菜的采集活动一年 四季都可进行,如田边地头的鱼腥草 (Houttuynia 
cordata)，生长在高山上的竹叶菜 (Maianthemum fuscum）嫩竹笋也是主要的采集对象。在野外调查 中，我们记录和采集了怒族村寨附近的野生常见食 用植物共 54 种 (表 1 )。

除高等植物外，怒族还采集近 20 种菌类供家庭 消费或出售,主要种类有: 银耳 (Tromella fuciformis)、木耳 ( Auricularia auricula)、黑怶木耳 ( Auricularia moelleri)、䝛极木耳 (Auricularia rugosissima)、 珊瑚菌 (Ramaria invalii)、鸡油菌 (Cantharellus cibarius)、云南鸡油菌 (Cantharellus yunnanensis)、牛肝菌 (Boletus spp.)、侧耳 (Pleurotus spp.)、红菇 (Russura spp. ) 等。

\section{2 怒族的药用植物}

怒江是药材王国桂冠上的宝石,由于怒族的生 存环境极为艰苦, 怒胞在长期的生产生活实践中积 累了一定的传统医药知识，尤其是通过生产实践和 文化积淀、文化交流逐渐认识了许多药用植物。怒 族虽有自己的语言, 但其文字极为简单, 因此他们长 期积累的战胜病魔的经验和知识主要是通过言传口 授的方式流传下来。通过调查,怒族尚未形成较为 完善的医药体系, 许多药物仅靠单方使用，少量发展 了复方。但是,怒族长期利用当地草药为人畜治病, 积累了丰富的药用植物知识, 有些药物还用来同外 界进行交换，以换取必要的生产生活用品。植物传 统草药至今仍是怒族聚居区居民所使用的主要药 物, 并有少数药用植物被人工栽培。

胡黄莲 (Picrorhiza scrophulariiflora), 是怒族常 用于与外界进行物资交换的一种重要药材。在怒江 丙中洛一带, 它大多生于海拔 3600 4400 m 被雪水 冲刷过的土地和高山流石滩上，在土壤肥沃、湿度较 大、腐殖质深厚、天然郁闭度为 $50 \%$ 左右的阳坡生 长最好。每年的 $8 \sim 9$ 月, 怒族人便上山采挖胡黄 莲, 制成干品后供交换或家庭用。怒族用它的根茎 入药, 有清热燥湿、杀虫、消疳的功能, 用于治疗小儿 疳积、目赤、潮热、黄㾝、痢疾、痔疮等病症。

黄连 (Coptis teeta) , 亦称云黄连, 是怒族 (同时 也是高黎贡山北部地区) 最重要的野生药材之一。 黄连是怒族用来治疗痢疾、目疾赤病等多种病痛的 常用药物, 可谓每家必备。野生黄连在丙中洛一带 分布于海拔 $1900 \sim 3000 \mathrm{~m}$ 的阴湿林下, 每年 $11 \sim$ 12 月, 是怒胞上山采挖野生黄连的时候。黄连采回
后，在日光下晒干或火塘上烘干，供自用和换取生产 生活物资。大约 50 年前, 怒族人从附近兄弟民族那 里学会了人工栽培黄连, 目前, 很多怒族的庭园里都 栽有黄连，以备急用。由于过度采集致使野生资源 减少, 贡山县各民族栽培黄连的面积和数量越来越 多。

获苓 (Poria cocos) ,为多孔菌科真菌, 也是怒族 采集利用和以物换物的一种名贵药材。获苓生长在 海拔 $1500 \sim 2600 \mathrm{~m}$ 山坡上的松树林下，怒族既用它 作为治疗疾病的常用药, 又用它作为强身健体的保 健品。除了采集野生获苓外,怒族人也人工栽培少 量获苓。

除上述 3 种药用植物外，怒族还采集利用其他 药用植物, 常见种类有石菖蒲 (Acorus tatarinowii) 、 车前 (Plantago erosa) 、漆树(也称 干漆”,Toxicodendron vernicifluum) 等 (表 2 )。

\section{3 怒族的观赏植物}

每年的农历 3 月 15 日, 为怒族的传统佳节

“鲜花节” ( 又佲 仙女节” “山母节”)。这一天，怒 族同胞都要采集庭院种植的最漂亮的鲜花带到仙女 洞，并摆放在洞中央，以表达对美好生活的向往并供 其他人观赏。即便家里没有正在盛开的鲜花,怒族 人也会到大山里去采挖一束鲜花,作为最珍贵的礼 物献给自己的节日。晚上, 围着鲜花载歌载舞。这 一仪式结束后,他们又将鲜花插在竹制筬貿里以便 长期观赏。在最近的一次实地调查中，我们有幸参 加并目睹了整个鲜花节的全过程, 并记录了他们平 时栽种在家里供观赏的鲜花。怒族的观赏植物主要 以杜鹃 (Rhododendron spp.) 为主, 兼有一些花大且 色彩艳丽的兰花、百合花 (Lilium spp.) 等 (表 3 )。

从表 3 可以看出,怒族庭院中栽培的观赏植物 和田边地头上保留下来的观赏植物，反映了他们对 当地植物资源的利用和保护知识, 具有十分鲜明的 特色。从形态上看, 怒族的观赏植物大都具有大型 花朵, 为喇叭状 (杜鹃、大百合、百合) 或花形奇特 (兰花类)。从颜色上看，以白色为主，兼有红色、黄 色等。从气味上看, 以清香型为主, 香味浓郁者很 少。从来源上看, 大多来自附近山野, 且有不少为当 地特有种, 如贡山凤兰 (Cymbidium gongshanense)、 独龙江杜鹃 (Rhododendron keleticum) 等。由此可 见 怒族文化的发展与其生存环境密不可分。 
表 1 怒族采集的重要野生食用植物

Table 1 Important wild edible plants collected by the Nu people

\begin{tabular}{|c|c|c|}
\hline $\begin{array}{l}\text { 物 种 } \\
\text { Species }\end{array}$ & $\begin{array}{l}\text { 食用部位 } \\
\text { Parts used }\end{array}$ & $\begin{array}{c}\text { 食 用 方 法 } \\
\text { Cooking methods }\end{array}$ \\
\hline 贡山猕猴桃 Actinidia kungshanensis & 成熟果实 Fruits & 生食 \\
\hline 疏毛猕猴桃 A. pilosula & 成熟果实 Fruits & 生食 \\
\hline 紫果猕猴桃 $A$. purpurea & 成熟果实 Fruits & 生食 \\
\hline 苋菜 Amaranthus tricolor & 嫩叶、种子 Young leaves, seeds & 嫩叶炒食、种子蒸熟食 \\
\hline 磨芋 Amorphopallus konjac & 块茎 Tubers & 加草木灰磨制成 豆腐” \\
\hline 马蹄 Angiopteris esculenta & 根、茎 Roots \& stems & 提取淀粉代粮 \\
\hline 刺葱木 Aralia chinensis & 嫩茎、叶 Young stems \& leaves & 炒食 \\
\hline 粉花羊蹄甲 Bauhinia variegata var. candida & 花 Flowers & 用水漂后炒食或制成干菜 \\
\hline 假通草 Brassaiopsis ciliate & 嫩茎、叶 Young stems \& leaves & 炒食 \\
\hline 水蕨菜 Callipteris escultenta & 嫩叶 Young leaves & 炒食 \\
\hline 荠菜 Capsella bursa-pastroris & 全草 Whole plant & 煮食、野菜 \\
\hline 碎米荠 Cardamine hirsute & 全草 Whole plant & 煮食、野菜 \\
\hline 大百合 Cardiocrinum giganteum & 鳞茎 Bulbs & 加工后蒸熟代粮或作蔬菜 \\
\hline 董棕 Caryota urens & 髓心 Marrow & 加工后烤食、代粮 \\
\hline 云南方竹 Chimonobambusa yunnanensis & 笋 Shoots & 炒食或制成干菜 \\
\hline 野芋 Colocasia esculenta & 块茎 Tubers & 煮食或蒸食、代粮 \\
\hline 鸡嗉子果 Dendrobenthamia capitata & 成熟果实 Fruits & 生食 \\
\hline 福贡龙竹 Dendrocalamus fugongensis & 笋 Shoots & 煮食或加工后做汤、野菜 \\
\hline 参薯 Dioscorea alata & 块根 Root tubers & 煮或蒸熟后代粮 \\
\hline 黄独 D. bulbifera & 块茎 Tubers & 加工后煮食或蒸食、代粮 \\
\hline 粘山药 D. hemsleyi & 块根 Root tubers & 煮或蒸熟后代粮 \\
\hline 五叶薯预 D. pentaphylla & 块茎 Tubers & 煮食或蒸食、代粮 \\
\hline 多依果 Docynia indica & 成熟果实 Fruits & 生食或切片晒干 \\
\hline 斜依箭竹 Fargesia declivis & 笋 Shoots & 煮食或加工后做汤、野菜 \\
\hline 空心箭竹 $F$. edulis & 笋 Shoots & 炒食或制成干菜 \\
\hline 驽刀箭竹 $F$. praecipua & 笋 Shoots & 煮食或加工后做汤、野菜 \\
\hline 大果榕 Ficus auriculata & 成熟果实 Fruits & 生食 \\
\hline 鼠菊草 Ganphalium offine & 嫩茎叶、花 Young leaves \& stems, flowers & 炒食或掺玉米面代粮 \\
\hline 油瓜 Hodgsonia macrocarpa & 种子 Seeds & 榨油 \\
\hline 鱼腥草 Houttuynia cordata & 全草 Whole plant & 凉拌或炒食 \\
\hline 小花八角 Illicium micranthum & 果、嫩叶尖 Fruits, young leaves & 煮食或作调料 \\
\hline 野八角 I. simonsii & 果、嫩叶尖 Fruits, young leaves & 煮食或作调料 \\
\hline 野核桃 Juglans cathayensis & 种仁 Seeds & 生食或烤食、野果 \\
\hline 香菌 Lentinus edodes & 全株 Whole plant & 煮食或炒肉、野菜 \\
\hline 川百合 Lilium davidii & 鳞茎 Bulbs & 煮食或蒸食、代粮 \\
\hline 三桠乌药 Lindera obtusiloba & 种子 Seeds & 榨油 \\
\hline 竹叶菜 Maianthemum fuscum & 嫩茎、叶 Young stems \& leaves & 炒食或制成干菜 \\
\hline 管花鹿药 $M$. henryi & 嫩茎、叶 Young stems \& leaves & 煮食、野菜 \\
\hline 长柱鹿药 $M$. oleraceum & 嫩茎、叶 Young stems \& leaves & 煮食或作汤、常用野菜 \\
\hline 紫花鹿药 $M$. purpureum & 嫩茎、叶 Young stems \& leaves & 煮食或作汤、常用野菜 \\
\hline 窄瓣鹿药 $M$. tatsiense & 嫩茎、叶 Young stems \& leaves & 煮食、野菜 \\
\hline 余甘子 Phyllanthus emblica & 果实 Fruits & 生食或腌制 \\
\hline 饭蕨 Pteridium revolutum & 根茎 Rhizomes & 提取淀粉代粮 \\
\hline 火炭母 Polygonum chinense & 嫩茎、叶 Young stems \& leaves & 煮食 \\
\hline 辣蓼 P. hydropiper & 嫩茎、叶 Young stems \& leaves & 煮食 \\
\hline 粉葛 Pueraria edulis & 块根 Root tubers & 生食或提取淀粉代粮 \\
\hline 大白花杜鹃 Rhododendron decorum & 花 Flowers & 用水漂后炒食或制成干菜 \\
\hline 黄钽子 Rubus obcordatus & 成熟果实 Fruits & 生食 \\
\hline 野慈姑 Sagittaria trifolia & 嫩茎、叶 Young stems \& leaves & 煮食 \\
\hline 鼻涕果 Saurauia napaulensis & 果 Fruits & 生食、野果 \\
\hline 少花龙葵 Solanum photeinocarpum & 嫩茎、叶 Young stems \& leaves & 炒食 \\
\hline 香椿 Toona sinensis & 嫩茎、叶 Young stems \& leaves & 凉拌或炒食 \\
\hline 刺通草 Trevesia palmata & 果及嫩茎、叶 Fruit \& young stems \& leaves & 炒食 \\
\hline 珍珠荚迷 Viburnum foetidum & 果 Fruits & 生食 \\
\hline
\end{tabular}


表 2 怒族常用的药用植物

Table 2 Medicinal plants commonly used by the Nu people

\begin{tabular}{|c|c|c|}
\hline $\begin{array}{c}\text { 物种 } \\
\text { Species }\end{array}$ & $\begin{array}{l}\text { 药用部位 } \\
\text { Parts used }\end{array}$ & $\begin{array}{l}\text { 主要功效 } \\
\text { Medicinal uses }\end{array}$ \\
\hline 乌敛莓叶五加 Acanthopanax cissifolius & 根、皮 Roots \& barks & 风湿、骨折 \\
\hline 吴茱英叶五加 A. evodiaefolius & 根、皮 Roots \& barks & 祛风、强筋骨、祛瘀血 \\
\hline 五加 A. gracilistylus & 根、皮及茎 Roots, barks \& stems & 水肿、阳隧、腰痛 \\
\hline 康定五加 A. lasiogyne & 根 Roots & 风湿、小儿筋骨瘘软 \\
\hline 白勒 A. trifoliatus & 根、茎、叶 Roots, stems \& leaves & 风湿麻木、咳嗽 \\
\hline 石菖蒲 Acorus tatarinowii & 根茎 Rhizomes & 健胃镇痛, 开倥豁痰 \\
\hline 象头花 Arisaema franchetianum & 块茎 Tubers & 颈淋巴结核、无名肿毒 \\
\hline 羊齿天门冬 Asparagus filicinus & 块根 Root tubers & 肺痑久咳、骨蒸潮热 \\
\hline 老鸦糊 Callicarpa giraldii & 全草 Whole plant & 内出血、血尿 \\
\hline 大百合 Cardiocrinum giganteum & 果实 Fruits & 清热、化痰、止咳 \\
\hline 苞花臭牡丹 Clerodendrum bracteatum & 根 Roots & 消肿 \\
\hline 黄连 Coptis teeta & 根茎 Rhizomes & 泻火解毒、燥湿杀虫 \\
\hline 鸡嗉子果 Cornus capitata & 果实 Fruits & 清热解毒、利尿、杀虫 \\
\hline 短荵万寿竹 Disporum bodinieri & 根 Roots & 食欲不振、筋骨疼痛 \\
\hline 黄独 Dioscorea bulbifera & 块茎 Tubers & 可催吐、解诸药毒 \\
\hline 薯莨 D. cirrhosa & 块茎 Tubers & 血瘀气滞、月经不调 \\
\hline 叉莈薯濒 D. collettii & 块茎 Tubers & 泌尿系统感染、乳糜尿 \\
\hline 薯蓣 D. oppoita & 块茎 Tubers & 消化不良、遗精、无名肿毒 \\
\hline 黄山药 D. panthaica & 根茎 Rhizomes & 清热解毒、九子疡 \\
\hline 贝母 Fritillaria cirrhosa & 鳞茎 Bulbs & 润肺散结、止咳化痰 \\
\hline 常春藤 Hedera nepalensis var. sinensis & 茎、叶 Stems \& leaves & 风湿性关节炎、肝炎、头晕 \\
\hline 白亮独活 Heracleum candicans & 根 Roots & 咳嗽、妇科病、牙痛 \\
\hline 北清香藤 Jasminum lanceolarium & 全草 Whole plant & 气管炎、腮腺炎、牙痛 \\
\hline 核桃 Juglans regia & 种仁、叶 Seeds \& leaves & 种仁补肾, 润肺、肠 \\
\hline 短片菜本 Ligusticum brachylobum & 根 Roots & 外感、头痛脑昏 \\
\hline 菜本 $L$. sinense & 根、茎 Roots \& stems & 妇人疝瘕、寒湿腹痛 \\
\hline 异叶梁王茶 Metapanax davidii & 根 Roots & 风湿骨痛、跌打损伤 \\
\hline 掌叶梁王茶 $M$. delavayi & 茎、皮 Stems \& barks & 喉炎 \\
\hline 肾蕨 Nephrolepis cordifolia & 全草 Whole plant & 清热、利湿、消肿、解毒 \\
\hline 假百合 Notholirion bulbiliferum & 鳞茎 Bulbs & 心胃气痛、胸间、咳嗽 \\
\hline 竹节参 Panax japonicus & 根茎 Rhizomes & 经闭、肺结核咯血 \\
\hline 长柱重楼 Paris forrestii & 根状茎 Rhizomes & 无名肿痛、蛇虫蛟伤 \\
\hline 毛叶重楼 P. mairei & 根状茎 Rhizomes & 清热解毒、消肿止痛 \\
\hline 多叶重楼 P. polyphylla & 全草 Whole plant & 肿毒、散血 \\
\hline 滇重楼 P. poylyphylla var. yunnanensis & 根茎 Rhizomes & 利小便、止血止痛 \\
\hline 皱叶重楼 P. rugosa & 全草 Whole plant & 无名肿毒、腮腺炎 \\
\hline 黑籽重楼 P. thibetica & 根状茎 Rhizomes & 心腹痛、白带 \\
\hline 五叶参 Pentapanax leschenaultia & 根皮、茎皮 Root barks \& stem barks & 气管炎、膀胱炎、疮毒 \\
\hline 怒江冷水花 Pilea salwinensis & 全草 Whole plant & 骨折、胃癌 \\
\hline 车前 Plantago erosa & 全草、种子 Whole plant \& seeds & 清热明目、利尿祛痰 \\
\hline 卷叶黄精 Polygonatum cirrhifolia & 根茎 Rhizomes & 补中益气、润肺祛痰 \\
\hline 点花黄精 $P$. punctatum & 根状茎 Rhizomes & 肺结核、风湿疼痛 \\
\hline 火炭母草 Polygonum chinensis & 全草 Whole plant & 清热解毒、利尿、凉血 \\
\hline 获苓 Poria cocos & 菌核 Fungus pit & 利尿、健脾胃、安神 \\
\hline 石韦 Pyrrosia lingua & 全草或叶 Whole plant or leaves & 利水通淋、清肺泻热 \\
\hline 吉祥草 Reineckia carnea & 全草 Whole plant & 咳嗽、吐血、哮喘 \\
\hline 川滇变豆菜 Sanicula astrantiifolia & 全草 Whole plant & 祛风湿、利筋骨 \\
\hline 叉柱岩菖蒲 Tofieldia divergens & 全草 Whole plant & 小便不利、疝气 \\
\hline 小窃衣 Torilis japonica & 果实 Fruits & 腹泻、活血消肿 \\
\hline 漆树 Toxicodendron vernicifluum & 树脂 Resin & 破淤、消积、杀虫 \\
\hline 黄花油点草 Tricyrtis maculata & 全草 Whole plant & 烦躁不安、活血化瘀 \\
\hline 延龄草 Trillium tschonoskii & 根茎 Rhizomes & 外伤出血、眩晕、高血压 \\
\hline 橙花开口箭 Tupistra aurantiaca & 根状茎 Rhizomes & 腰腿痛、跌打损伤 \\
\hline
\end{tabular}


表 3 怒族庭园栽种及农地中保留的常见观赏植物

Table 3 Common cultivated ornamental plants in the homegarden and retained in farming lands by the $\mathrm{Nu}$ people

\begin{tabular}{|c|c|}
\hline $\begin{array}{l}\text { 物 种 } \\
\text { Species }\end{array}$ & $\begin{array}{l}\text { 生 活 型 } \\
\text { Life form }\end{array}$ \\
\hline 大百合 Cardiocrinum giganteum & 多年生草本 Perennial herb \\
\hline 长叶兰 Cymbidium erythraeum & 多年生草本 Perennial herb \\
\hline 惠兰 $C$. faberi & 多年生草本 Perennial herb \\
\hline 多花兰 C. floribundum & 多年生草本 Perennial herb \\
\hline 朵朵香 $C$. goeringii & 多年生草本 Perennial herb \\
\hline 贡山凤兰 C. gongshanense & 多年生草本 Perennial herb \\
\hline 虎头兰 C. hookerianum & 多年生草本 Perennial herb \\
\hline 黄蝉兰 C. iridioides & 多年生草本 Perennial herb \\
\hline 寒兰 $C$. kanran & 多年生草本 Perennial herb \\
\hline 兔耳兰 C. lancifolium & 多年生草本 Perennial herb \\
\hline 莎草兰 $C$. elegans & 多年生草本 Perennial herb \\
\hline 碧玉兰 C. lowinum & 多年生草本 Perennial herb \\
\hline 豆瓣兰 $C$. wilsonii & 多年生草本 Perennial herb \\
\hline 黄花杓兰 Cypripedium flavum & 多年生草本 Perennial herb \\
\hline 野百合 Lilium browii & 多年生草本 Perennial herb \\
\hline 川百合 $L$. davidii & 多年生草本 Perennial herb \\
\hline 宝兴百合 $L$. duchartrei & 多年生草本 Perennial herb \\
\hline 怒江百合 $L$. henricii & 多年生草本 Perennial herb \\
\hline 尖被百合 L. lophophorum & 多年生草本 Perennial herb \\
\hline 紫斑百合 L. nepalense & 多年生草本 Perennial herb \\
\hline 紫花百合 $L$. souliei & 多年生草本 Perennial herb \\
\hline 尖果洼瓣花 Lloydia oxycarpa & 多年生草本 Perennial herb \\
\hline 西藏洼瓣花 L. tibetica & 多年生草本 Perennial herb \\
\hline 宿鳞杜鹃 Rhododendron aperantum & 矮小灌木 Shrublets \\
\hline 瘤枝杜鹃 R. asperulum & 灌木 Shrub \\
\hline 窄叶杜鹃 $R$. araiophyllum & 灌木或小乔木 Shrub or arbor \\
\hline 夺目杜鹃 $R$. arizelum & 灌木或小乔木 Shrub or arbor \\
\hline 矮柱杜鹃 $R$. brachyanthum & 小灌木 Shrub \\
\hline 毛喉杜鹃 R. cephalanthum & 小灌木 Shrub \\
\hline 绢毛杜鹃 R. chaetomallum & 灌木 Shrub \\
\hline 纯黄杜鹃 R. chrysodoron & 小灌木 Shrub \\
\hline
\end{tabular}

灌木, 花具香味 Shrub with fragrant flowers

矮小灌木 Shrub

灌木或小乔木 Shrub or arbor 灌木或小乔木 Shrub or arbor 灌木 Shrub

灌木或小乔木 Shrub or arbor 灌木或小乔木 Shrub or arbor 灌木 Shrub

灌木或小乔木 Shrub or arbor

灌木, 通常附生 Shrubs, normally epiphytic

矮小灌木 Small shrub

灌木 Shrub

灌木 Shrub

匍匐状矮小灌木 Creeping shrublets

灌木 Shrub

灌木 Shrub

匍匐小灌木 Creeping shrublets

灌木或小乔木 Shrub or arbor 灌木 Shrub

灌木或小乔木 Shrub or arbor 灌木或小乔木 Shrub or arbor 小灌木 Shrublets 小乔木或乔木 Arbor

\section{4 怒族的文化、宗教植物}

怒族没有统一的宗教。早期的怒族虽然信奉原 始宗教, 但原始宗教不但未能将怒族各支系统一起 来,反而使得各支系所信仰的原始宗教在内容上表 现出较大的差异。约在 300 年前, 喇嘛教开始传入 贡山。19 世纪末 20 世纪初, 天主教、基督教相继传 入怒江,并在怒族中找到了相应的信徒（陶天麟, 1997 )。正因为如此，丙中洛的怒胞所信奉的宗教 达 4 种之多。不同的教派有不同的信仰,也就有不 同的图腾崇拜。怒胞选择了不同的植物赋予其不同 的文化及宗教意义。例如金丝桃科的芒种花 (Hypericum uralum) 常被扞插在屋前空地上, 以祭天神。 莎草科的山稗子 (Carex baccans) 被怒胞用来燃烧以 驱邪除秽。而房前屋头挂山茶科植物红木荷 (Schi$m a$ wallichii) 则表示吉祥如意。在野外调查中, 还记 录和采集了其他的文化、宗教植物 (表 4)。

\section{5 讨论}

5.1 怒族传统的植物多样性利用和管理方式的合 理性与局限性

怒族传统的植物多样性利用和管理是以道德的 平等、宗教的信仰、习惯法的约束、头人的管理为主 要特点, 而主要的管理是以头人的协调为主进行的。 除了宗教的畏惧使人们不敢肆意破坏大自然而得罪 神灵，从而约束着人与自然的关系外，其余的管理主 要是为了确保人与人之间在利用植物资源上的关系 尽可能平等，尽可能化解他们之间的矛盾。总的说 来, 这种管理体现的是: 人是可以尽自己的能力去利 用植物资源的, 以求能获得足够的食物, 但不能由此 而引起村内或村间、族内或族间的矛盾。在人的生 活要求很低, 而资源又较多的时候, 可以通过土地轮 耕的方式实现人与植物的平衡，因为在怒江流域低 海拔气候暖湿的地方, 森林天然更新速度较快, 通过 轮歇方式，人们可以长期持续利用森林。随着人口 增多, 轮歇年限缩短, 森林恢复能力下降, 这种管理 体系必定导致森林的全面破坏,最后人们也不得不 去寻找新的森林，去破坏一个新的生态系统。

另外,由于怒族医药发展尚未完善,对药用植物 的利用效益较低，往往造成一定程度的资源浪费，需 要对怒族医药作深入调查研究,进一步发掘优秀的 民族医药传统知识,使其在当地社会经济发展中发 
表 4 怒族的文化、宗教植物

Table 4 The plants for cultural and religious use by the $\mathrm{Nu}$ people

$\begin{array}{r}\text { 物 种 } \\ \text { Species } \\ \hline \text { 菖蒲 Acorus calamus }\end{array}$

\section{多星韭 Allium wallichii}

五裂点地梅 Androsace geraniifolia 茶梨 Anneslea fragrans

牡蒿 Artemisia japonica

鞍叶羊蹄甲 Bauhinia brachycarpa 松风草 Boenninghausenia albiflora 三褶虾脊兰 Calanthe triplicata 山稗子 Carex baccans

高山栲 Castanopsis delavayi 冬海棠 Cerasus cerasoides

香桂 Cinnamomum subavenium 贝母兰 Coelogyne barbata 竹节草 Commelina diffusa 马桑 Coriaria nepalensis 青冈 Cyclobalanopsis glauca 虎头兰 Cymbidium hookerianum 云南常山 Dichroa yunnanensis 吴茱英 Evodia rutaecarpa 棱子吴莫 E. subtrigonosperma 鼠曲草 Gnaphalium affine 异莈一笼鸡 Gutzlaffia lyi 姜花 Hedychium coronarium 五风藤 Holboellia latifolia 刺叶冬青 Ilex bioritzensis 野八角 Illicium simonsii 云南蓞尾 Iris forrestii 鸡血藤 Kadsura interior 怒江红杉 Larix speciosa 扁球羊耳蒜 Liparis elliptica 清香木姜子 Litsea euosma 鸡冠滇丁香 Luculia yunnanensis 忽地笑 Lycoris aurea 珍珠花 Lyonia ovalifolia 喀西沼兰 Malaxis khasiana 沿阶草 Ophiopogon bodinieri 清香木 Pistacia weinmannifolia 华山松 Pinus armandii 侧柏 Platycladus orientalis 响叶杨 Populus yatungensis 齿叶报春 Primula serratifolia 香茶菜 Rabodsia lophanthoides 吉祥草 Reineckia carnea 万年青 Rohdea japonica 茅莓 Rubus parvifolius 怒江柳 Salix nujiangensis 多脉水冬哥 Saurauia polyneura 穗序鹅掌柴 Schefflera delavayi 银木荷 Schima argentea 绶草 Spiranthes sinensis 大籽山香圆 Turpinia macrosperma
Reasons for worship

震慑植物，用于制鬼避邪

传言植物，用于求婚

表意植物，表示和睦相处

香源植物，勾通鬼神，求福免灾

洁净植物, 用于驱邪除净

驱除禳解植物，用于驱妖除魔

礼仪植物，用于年节送礼

表意植物, 表示暗恋对方

洁净植物, 用于驱邪除净

驱除䘻解植物, 用于驱妖除魔

礼仪植物, 用于开业送礼

神树，祭祀天神

表意植物，表示暗恋对方

表意植物, 表示和睦相处

洁净植物, 用于驱邪除净

吉祥植物, 用于祝福老人

传言植物，用于求婚

礼仪植物，用于开业送礼

传言植物，用于求婚

神树，祭祀天神

礼仪植物, 用于年节送礼

驱除禳解植物，用于驱妖除魔

表意植物, 用于和睦相处

表意植物, 用于祝福对方健康

吉祥植物, 用于祝福老人

香源植物, 勾通鬼神, 求福免灾

传言植物，用于求婚

表意植物，用于祝福对方健康

震慑植物，用于制鬼避邪

表意植物, 表示暗恋对方

神树，祭祀天神

香源植物，勾通鬼神，求福免灾

传言植物，用于求婚

洁净植物, 用于驱邪除净

表意植物，表示暗恋对方

礼仪植物，用于年节送礼

香源植物，勾通鬼神，求福免灾

吉祥植物, 用于祝福老人

洁净植物, 用于驱邪除净

驱除禳解植物, 用于驱妖除魔

表意植物, 表示和睦相处

礼仪植物, 用于年节送礼 吉祥植物, 用于祝福老人 吉祥植物，用于祝福老人

震慑植物, 用于制鬼避邪 震慑植物，用于制鬼避邪 礼仪植物, 用于开业送礼 礼仪植物，用于年节送礼 吉祥植物, 用于祝福老人 表意植物，表示暗恋对方 神树，祭祀天神
赋予意义
挥更大的作用。

5.2 怒族传统的植物多样性利用和管理方式中存 在着朴素的生态保护意识

怒族自古以来就是从事刀耕火种轮歇栽培、采 集和狩猎的山地民族, 至今仍保留着较完整的民族 传统农耕文化。在古朴的传统农耕文化中, 蕴含着 丰富的对植物多样性管理和利用的科学内涵。例 如怒族并不是对任何森林都进行刀耕火种轮歇栽 培的，他们总喜欢选择树木不太粗大、土层深厚、水 湿条件好的地方进行农耕生产,而其他地方的森林 则被世代保存下来,供砍伐木材建屋和砍伐薪柴取 火，也可以去狩猎、去采集各种类型的森林小产品。 这种对环境和植物多样性的分类利用与管理, 其实 己经考虑到了生态关系，从而不会造成对居住地全 部森林的毁坏, 达到永续利用的目的。

宗教信仰中的保护意识就更加明显了，比如不 能随意砍伐大树, 否则树神会怪罪。狩到猎物后, 头 脚要献鬼、献猎神，以求其保佑今后还可以狩到猎 物。在这种观念里 怒族并非将动物赶尽杀绝, 而是 希望能够永续利用。他们每年都要祭祀山神, 过去 还在家里供奉着山神, 向山神祈祷, 以保佑他们的生 产、生活能和顺美满，除去宗教的色彩，这其实是反 映了他们内心深处与自然和谐共处的愿望和意识。

此外,怒族早已发现了一些朴素的生态常识,比 如他们已经发现, 森林繁茂的地方, 水也多,且流得 平稳, 不会泛滥, 所以他们认为森林中储存有水, 可 以源源不断地释放出来。

5.3 怒族传统的植物多样性利用和管理观念正在 发展变化

近年来, 随着社会各界对森林重要性认识的提 高怒族群众对植物多样性利用与管理的观念也发 生了很大变化, 传统的刀耕火种轮歇栽培的生产方 式已逐年减少,他们已逐渐认识到这种方式的局限 性。部分怒族已经在轮歇地中栽种速生的冬瓜树 (Alnus nepalensis) , 以使森林得到快速恢复, 进行事 实上的土地肥力恢复、退耕还林和治理水土流失。 这些变化体现了怒族对森林与自身关系的新认识, 这种变化应该得到外界社会的关注与鼓励。同时， 进一步发掘优秀民族传统知识, 并把这些知识还给 他们,应受到科学工作者和政府的重视。 


\section{6 建议}

不同的生存环境 (尤其是生物环境) 造就了全 世界不同民族和不同地区丰富多彩的文化,这就是 文化多样性 (cultural diversity)。文化多样性和生物 多样性是密不可分的整体 (Sinha，1996)。文化塑 造着环境，不仅决定着个人或集体对自然资源的利 用和管理，而且改变着整个地球的生态系统和生物 多样性 (Arizpe，1996)。在当今的生物多样性保护 和管理中，文化多样性保护是不容忽视的重要方面， 其重要性已越来越被从事生物多样性科学的研究者 所认识和接受, 并且还出现了“生物文化多样性” (biocultural diversity) 的术语（Dasmann，1995), 进 一步强调了两者之间的关系。

人类在长期和自然作斗争的过程中，对如何做 到和自然的和平共处、和谐统一,已积累了丰富的经 验，这些经验在民间传统文化上都有充分的反映。 我国民族众多，历史悠久，各民族传统文化相当丰 富，因此，利用文化的多样性来为植物多样性的利 用、管理和保护服务完全成为可能。

此外，不同民族在历史形成过程中，由于所处的 自然地理环境不同，其宗教文化信仰的内容和方式 也各不相同，特别在那些地理上封闭、文化相对落后 的少数民族地区更是如此。从这一点来说, 利用传 统知识和文化信仰来增强对植物多样性的保护, 是 现代生态环境保护的合理途径之一。

再者, 少数民族聚集地区往往是生物多样性和 文化多样性最为丰富的地区，保护当地的植物多样 性符合当地人民的利益。为此，无论从文化上、生态 上、长远利益上都会得到当地土著居民的理解和支 持。由此可见，充分利用文化多样性服务于现代自 然生态环境的保护具有很大的可行性和现实意义。

然而，在近 40 年来由于经济的发展和主流文化 的影响，民族传统文化中许多优秀的部分，包括对自 然环境资源管理的传统知识、对植物多样性保护的 优良传统、对植物资源持续利用的经验，正随着民族 传统文化的消失而消失，这种消失是不可逆转的。 如何有效地进行传统文化多样性的保护已是一个刻 不容缓的议题。面对严峻的现实，我们应该动员社 会各界的有关力量，立即着手拯救，尽可能广泛、全 面而深入地收集和研究民族文化中与植物多样性有 关的部分，并进行编目和存储，以便应用于将来的植
物多样性保护与利用之中。

最后，不论是民族传统文化或是文化多样性，其 在植物多样性的利用、保护和管理中的应用都属于 传统管理的范畴。这种管理模式是在生产力比较低 下, 为满足较低社会经济需求的历史背景下逐渐形 成的。今天 其中的很多内容仍然发挥着较好的作 用，比如少数民族中头人的协调，公平、平等的道德 观念，对自然的宗教祭祀，这些都有利于约束人们的 行为, 解决相互间的纠纷。然而时代不同了, 特别是 目前我国正在建设社会主义市场经济体系,社会生 产力的发展和市场观念也深深地影响着相对落后的 少数民族地区。现在的少数民族不可能象过去那样 依赖族群，依赖整个村子的集体力量而生存，他们已 经有了较强的平等独立地参与社会、参与市场的意 识和能力, 也有了更高的经济文化需求。在这种新 的时代背景下, 对作为一种资源的森林, 单靠传统观 念、习俗进行管理, 约束力就不那么强了, 而需要最 具公平、公正特点的法律的管理、政策的管理，也需 要更多的科学文化知识，从而做到更科学合理的利 用与管理。所以，无论是当地土著居民自己，还是林 业部门和自然保护区管理机构,都应把土著居民的 传统观念、习俗与现代的科技知识 (比如造林、节能 等科技知识)、法律政策结合起来，才能对植物多样 性的利用和保护进行最有效的管理。

致 谢 本所李恒研究员在植物凭证标本的鉴定过 程中给予极大的帮助, 贡山县高黎贡山国家级自然 保护区贡山管理局的李向前先生参加部分野外工 作，特致谢忱！

\section{参考文献}

Aba R. M. and Brito S. 1996. How to study the pharmacology of medicinal plants in undeveloped countries. Journal of Ethnopharmacology, 54: $131-138$.

Arizpe L. 1996. Culture and environment. Nature and Resources, 32(1): 1 .

Begosst A. 1996. Use of ecological methods in ethnobotany: diversity idices. Economic Botany, 50: $280-289$.

Changkija S. 1996. Ethnobotanical folk practices and beliefs of the Ao-Nagas in Nagaland, India. Ethnobotany, 8: 26 30 .

Dasmann R. F. 1995. The importance of cultural and biological diversity. In: Oldfield M. and Alcorn J. (eds.), Biodiversity: Culture, Conservation and Ecodevelopment. Westview Press, Boulder, San Francisco, Oxford, 9-15.

Duan L(段伶)。1991. Nu People(怒族)。 Nationality Press, 
Beijing, 25 - 180. (in Chinese)

Editing Committee for Introduction of Gongshan $\mathrm{Nu}$ and Dulong Autonomous County (贡山独龙族、怒族自治县概况编写 组). 1981. General Situation of Gongshan Nu and Dulong Autonomous County (贡山独龙族、怒族自治县概况). Yunnan Nationality Press, Kunming, 33 - 38. ( in Chinese)

Etkin N. 1993. Anthropological methods in ethnopharmacology. Journal of Ethnopharmacology, 38: 93 - 104.

Hedberg I. 1993. Botanical methods in ethnopharmacology and the need for conversation of medicinal plants. Journal of Ethnopharmacology, 38: $121-128$.

Lipp F. J. 1989. Methods for ethnopharmacology field work. Journal of Ethnopharmacology, 25: 139 - 150.

Liu L-H(刘伦辉), Dao Z-L(刀志灵), Guo H-J(郭辉军) and Li H(李恒). 2000. Vegetation of Gaoligong Mountains. In: Li H( 李恒), Guo H-J (郭辉军) and Dao Z-L(刀志 灵) (eds.), Flora of Gaoligong Mountains (高黎贡山的植 被). Science Press, Beijing, 6-48. (in Chinese)

Liu A-Z(刘爱忠), Pei S-J(裴盛基) and Chen S-Y(陈三阳). 2000. An investigation and study on the plant worship by Yi people in Chuxiong, Yunnan. Chinese Biodiversity(生物 多样性), 8(1): 130-136. (in Chinese)

Long C. L. and Wang J. R. 1995. Ethnobotany of Jinuo nationality in Xishuangbanna, Southwest China. I. Edible plants. Ethnobotany, 7( $1-2)$ : $39-49$.

Long C-L(龙春林), Li H(李恒), Dao Z-L(刀志灵) and Zhou Y-L( 周翊兰) . 1999a. Ethnobotanical studies in Gaoligong Mountains. I. The Lemo people. Acta Botanica Yunnanica (Suppl. XI) (云南植物研究) : $131-136$. (in Chinese)

Long C-L( 龙春林), Li H( 李恒), Zhou Y-L( 周翊兰), Dao ZL(刀志灵) and A B-Z(阿部卓). 1999b. Ethnobotanical studies in Gaoligong Mountains. II. The Dulong Ethnic Group. Acta Botanica Yunnanica (Suppl. XI) (云南植物 研究) : $137-144$. (in Chinese)

Long C-L(龙春林) and Wang J-R(王洁如). 1996. Participatory Rural Appraisal: An Introduction to the Principle, Methodology and Application (参与性农村评估的原理方 法与应用). Yunnan Science \& Technology Press, Kunming, $1-51$. ( in Chinese)

Long C-L( 龙春林), Zhang F-Y (张方玉), Pei S-J(裴盛基) and Chen S-Y(陈三阳). 1999c. Impacts of traditional culture of $\mathrm{Yi}$ nationality upon biodiversity in Zixi Mountains area, Yunnan. Chinese Biodiversity (生物多样性), 7(3): 245 - 249. (in Chinese)

Long C-L(龙春林)，Zhou Y-L(周翊兰) and Dao Z-L(刀志 灵). 2000. Introduction to Ethnobotany of Gaoligong Mountains. In: Li H( 李恒), Guo H-J (郭辉军) and Dao Z-L(刀志灵) ( eds.), Flora of Gaoligong Mountains ( 高 黎贡山植物). Science Press, Beijing, 365 - 373. ( in Chinese)

Pei S-J(裴盛基). 1982. Preliminary Study of Ethnobotany in Xishuangbanna, People's Republic of China. In: Collected Research Papers on the Tropical Botany (热带植物研究论 文报告集). The People's Publishing House, Kunming, 16 - 32. (in Chinese)
Pei S. J. 1985. Some effects of Dai people's cultural beliefs and practices upon the environment of Xishuangbanna, Yunnan, China. In: Hutterer C., Rambo A. T. and Lovelace G. (eds.), Cultural Values and Human Ecology in Southeast China (Chapter 13). The University of Michigan, Ann Arbor, $321-339$.

Pei S-J(裴盛基) and Long C-L(龙春林). 1998. Applied Ethnobotany (应用民族植物学). Yunnan Nationality Press, Kunming, 70 - 86. (in Chinese)

Rao R. R. 1996. Traditional knowledge and sustainable development: key role of ethnobiologists. Ethnobotany, 8: 14 24.

Sinha P. K. 1996. Conservation of cultural diversity of indigenous people essential for protection of biological diversity. In: Jain S. K. ( ed.), Ethnobotany in Human Welfare. Deep Publication, New Delhi, 280 - 283.

Tao T-L(陶天麟). 1997. The Cultural History of Nu People (怒 族文化史). Yunnan Nationality Press, Kunming, 17 228. (in Chinese)

Upadhye M. S., Kumbhojkar M. S. and Kulkarni D. K. 1997. Ethno-medico-botany of some sacred plants of Western Maharashtra. Ethnobotany, 9: 65 - 68.

Viswanathan M. B. 1997. Ethnobotany of the Malayalis in North Arcot District, Tami Nadu, India. Ethnobotany, 9: $77-79$.

Waller D. P. 1993. Methods in ethnopharmacology. Journal of Ethnopharmacology, 38: $189-195$.

Wang N-S(汪宁生). 1996. Cultural Anthropological Survey, A Method to Understand Our Society (文化人类学调查 正确认识社会的方法). Antique Press, Beijing, 14-35. (in Chinese)

Xu Z-F(许再富) and Liu H-M(刘宏茂). 1995. Palm leaves Buddhism Sutra culture of Xishuangbanna Dai and plant diversity conservation. Chinese Biodiversity(生物多样性), 3 (3) : $174-179$. (in Chinese)

Yang C-Y (杨昌岩), Pei C-X (裴朝锡) and Long C-L (龙春 林). 1995. A preliminary recognition on the relationship between the traditional culture of Dong nationality and biodiversity. Chinese Biodiversity (生物多样性), 3 (1): $44-45$. (in Chinese)

Yunnan Editing Committee (云南省编辑委员会)。1981. The Investigation of Social History of Nu People(怒族社会历史 调查). Yunnan Nationality Press, Kunming, 15 - 106. (in Chinese)

Zhang X-S(张新时). 1995. Notes on biodiversity. In: Biodiversity Committee of the Chinese Academy of Sciences (中 国科学院生物多样性委员会) and Department for Wildlife and Forest Plants Protection, the Ministry of Forestry (林业部野生动物与森林植物保护司) (eds.), Advances in Biodiversity Research: Proceedings of the First National Symposium on the Conservation and Sustainable Use of Biodiversity (生物多样性研究进展: 首届全国生物多样 性保护和持续利用研讨会论文集). Chinese Science and Technology Press, Beijing, 10-12. (in Chinese)

(责任编辑：孙大川) 